\title{
Solitary Plasmacytoma with Minimal Marrow Involvement
}

\author{
Khalife Mustapha* \\ Assistant professor of medicine oncology \\ *Corresponding author: Khalife Mustapha, Assistant professor of medicine oncology, USA
}

\begin{tabular}{|c|c|}
\hline ARTICLE INFO & ABSTRACT \\
\hline Received: 慧 April 18, 2019 & Citation: Khalife Mustapha*. Solitary Plasmacytoma with Minimal Marrow Involvement. \\
\hline & Biomed J Sci \& Tech Res 17(3)-2019. BJSTR. MS.ID.003017. \\
\hline
\end{tabular}

\section{Introduction}

Plasma cell dyscrasias belongs to a group of malignancies characterized by the malignant proliferation of a single plasma cell clone. Plasma cell dyscrasias can present as a single lesion (solitary plasmacytoma with or without limited bone marrow involvement) or as multiple lesions (multiple myeloma) or as no detectable lesions (MGUS, smoldering myeloma or multiple myeloma). The reason why certain plasma cell neoplasm evolves into plasmacytoma and no other plasma cell dyscrasias including multiple myeloma is not quite understood. It is very important to differentiate these entities since their management, treatment and prognosis vary considerably.

\section{Definition}

Solitary plasmacytoma is a plasma cell malignancy consisting of a localized, single clone of plasma cells in the absence of anemia, hypercalcemia, renal insufficiency, or multiple lytic bone lesions considered to be features of multiple myeloma.

\section{Clinical Presentation of Solitary Plasmacytoma}

Solitary plasmacytomas most commonly occur in bone and is referred to as solitary plasmacytoma of bone (SPB) also called osseous plasmacytoma. Solitary plasmacytomas less frequently occur in soft tissues and are referred to as extramedullary plasmacytoma.

Most patients with plasmacytomas present with pain (skeletal pain from a bone lesion or a pathologic fracture) or neurologic compromise (from cord compression). Less commonly, solitary plasmacytoma can present as a palpable mass (proliferation in soft tissue).

\section{Laboratory Findings}

Typically, patients with SPB have no anemia, renal failure, hypercalcemia or any additional lytic bone lesions. Approximately $60 \%$ of patients with SPB have no clonal plasma cells on bone marrow. However, about $40 \%$ of patients with apparent SPB have evidence of clonal plasma cells on bone marrow examination (typically less than 10\%) and these are referred to as solitary plasmacytoma with limited bone marrow involvement [1].

\section{Treatment}

Most patients with solitary plasmacytoma will be staged as Durie-Salmon stage I myeloma. In the absence of end organ damage and if they have less than $10 \%$ clonal plasma cells in the bone marrow, these patients are considered to have solitary plasmacytoma with limited bone marrow involvement (or just solitary plasmacytoma in case of no monoclonal plasma cells in the bone marrow) and are typically treated with radiation.

If patients have more extensive clonal plasmacytosis in the bone marrow (more than 10\%), systemic therapy can be considered, although there are limited data available to guide therapy.

\section{Prognosis}

Patients with solitary plasmacytoma with limited bone marrow involvement are treated in a similar fashion to SPB but have a higher risk of progression to symptomatic myeloma with a $60 \%$ chance of recurrence or progression within three years $[2,3]$.

\section{Differential Diagnosis}

It is important to distinguish SPB both from other diseases since management, prognosis is different. Patients with multiple 
myeloma typically have lytic lesions, anemia, hypercalcemia, and/ or renal insufficiency. These patients also tend to have more than $10 \%$ plasma cell on bone marrow. Patients with POEMS syndrome (also referred to as osteosclerotic myeloma: Polyneuropathy, Organomegaly, Endocrinopathy, Monoclonal protein, Skin changes) typically present with peripheral neuropathy, osteosclerotic lesions, organomegaly, endocrinopathy (excluding diabetes mellitus or hypothyroidism), Castleman's disease, typical skin changes, edema, and/or papilledema. These patients typically have elevated serum vascular endothelial growth factor (VEGF) levels.

\section{ISSN: 2574-1241}

DOI: 10.26717/BJSTR.2019.17.003017

Khalife Mustapha. Biomed J Sci \& Tech Res

This work is licensed under Creative Commons Attribution 4.0 License

Submission Link: https://biomedres.us/submit-manuscript.php

\section{References}

1. Warsame R, Gertz MA, Lacy MQ Kyle RA, Buadi F, et al. (2012) Trends and outcomes of modern staging of solitary plasmacytoma of bone. Am J Hematol 87(7): 647-651.

2. Paiva B, Chandia M, Vidriales M, Colado E, Caballero Velázquez T, et al. (2014) Multiparameter flow cytometry for staging of solitary bone plasmacytoma: new criteria for risk of progression to myeloma. Blood 124(8): 1300-1303.

3. Hill QA, Rawstron AC, de Tute RM, Owen RG (2014) Outcome prediction in plasmacytoma of bone: a risk model utilizing bone marrow flow cytometry and light-chain analysis. Blood 124(8): 1296-1299.

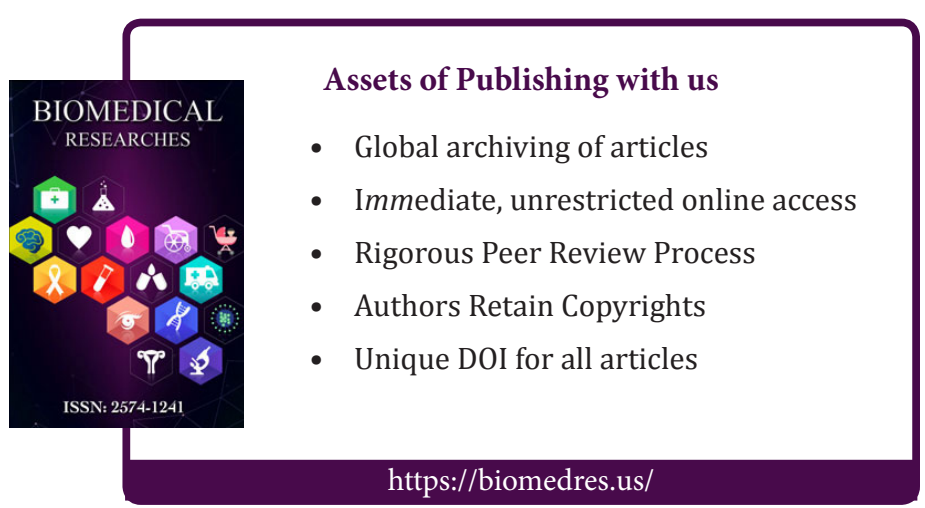

